subjects. The author supports alterations of previous mapping whereby outcrops formerly shown as Trias are now shown as Carboniferous or Permo-Carboniferous by new discoveries of calcareous rocks but no palaeontological evidence has been found. A feature of the publication is the number of rock-analyses, comprising some of granite by Mr. J. C. Shenton, spectroscopic analyses of rarer constituents of granite by Messrs. Marsman and Co., Manila, and analyses of schists by Mr. G. M. Harral. Part of the area described has produced gold as well as tin for many years. Records of output of gold are given from 1895 to 1937 , the lowest being $548 \mathrm{oz}$. in 1902 , the highest $7,789 \mathrm{oz}$. in 1936 . The memoir is short, but economics rightly occupy more than half the pages, while many will not miss lengthy descriptions of geological detail. Dr. Ingham, who is Mining Geologist on the staff, is to be congratulated on an excellent piece of work.

J. B. S.

\title{
CORRESPONDENCE.
}

\section{PROBLEMS OF AMMONITE NOMENCLATURE.}

Sir,-Reading (with the fullest sympathy for the conclusions) the article by Dr. L. F. Spath in this Magazine for February, 1939, I have met with two points I cannot follow.

How could J. P. Smith's selection of Amm. neojurensis as the genotype of Rhacophyllites in 1927 be possibly effective when that spècies had been removed to another genus fifteen years before?

How "supposing J. P. Smith had mentioned Amm. tortisulcatus as the type " of Rhacophyllites would it "throw out Sowerbyceras"? Surely such a mention would have been a mere nullity as $\mathrm{Amm}$. tortisulcatus had been removed from Rhacophyllites over thirty years before.

It seems hardly rational that a species which has been removed from genus A to genus B should continue to be eligible as the type of genus $\mathrm{A}$.

IVY Farm House, MUNDestey. 13 th February, 1939.

R. M. Brydone. 